\title{
Experimental Studies of Sublimation of Highly Volatile Ices in Relevance to the Ices of the Solar System
}

\author{
Jacek LELIWA-KOPYSTYŃSKI ${ }^{1}$, Miquel A. SATORRE ${ }^{2}$, \\ and Carmina SANTONJA ${ }^{2}$ \\ ${ }^{1}$ University of Warsaw, Institute of Geophysics, Warsaw, Poland \\ e-mail: jkopyst@mimuw.edu.pl \\ ${ }^{2}$ Polytechnic University of Valencia, Department of Applied Physics, \\ Alcoy, Spain
}

\begin{abstract}
Studies of sublimation of complex ices prepared by deposition of gaseous $\mathrm{CO}, \mathrm{CH}_{4}, \mathrm{~N}_{2}$, and $\mathrm{NH}_{3}$ molecules on a cold plate have been performed. The low pressure and low temperature system was used: $10^{-9}-10^{-5}$ mbar and the lowermost temperature $10 \mathrm{~K}$. Diagnostic of composition of evaporates (at an actual temperature) was done by means of the mass spectrometer. The latter allowed following simultaneously the partial pressure of five different ions or radicals escaping from the substrate. It has been found that highly volatile molecules that were used simultaneously with the low volatile ones to form the complex ices (mixtures or clathrates) present a different sublimation pattern than the sublimation of pure high-volatile ices. In particular, the high-volatile component sublimes at two or even three different temperature regimes: At low temperature that is typical for sublimation of this component, as well as at much higher temperatures. This effect seems to be important when degassing and outbursts from cometary nuclei are considered. It can be also important for modeling of cryovolcanic processes on the icy satellites.
\end{abstract}

Key words: clathrates, comets, ices, sublimation, satellites. 


\section{INTRODUCTION: ICES IN THE SOLAR SYSTEM}

The word "ice" is commonly reserved for solidified water. However, its plural form "ices" concerns water ice as well as the different chemical compounds that at the pressure and temperature conditions typical for the Earth surface remain mostly in liquid or gaseous states.

Ices are ubiquitous at least in the two classes of the Solar System bodies: The icy satellites of the giant planets and the cometary nuclei. Most probably, ices are also the important components of the Kuiper Belt Objects (KBOs). For all the three classes of bodies, the ices are permanently observed or, at least, they have been detected on their surfaces. The densities of the icy satellites, the cometary nuclei, and the KBOs (all of them are commonly classified as "the icy bodies") are close to density of the water ice and much less than the densities of the minerals. This indicates that the ices are important or even prevailing bulk components of the icy bodies. Pressure $p$ and temperature $T$ are the most important thermodynamic parameters determining properties of ices inside the icy bodies or on their surfaces. However, the $(p, T)$ influence on the ices inside the icy bodies or on the surfaces of them differ substantially. Inside, at a given depth, with the exception of a few sub-surfaces decimeters or meters, the $(p, T)$ are constant or they change very slowly. However, the surfaces are illuminated by the solar radiation whose local intensity depends on the body-centered ("geographical") latitude. Moreover, insulation varies following a few periods of very different duration. They are the periods of the rotation ("diurnal" period), of the revolution ("annual" period), and that of the precession.

Due to solar illumination, the sublimation processes start and develop with different intensity for different ices. The pressure on the surface of the atmosphere-less bodies is almost zero and therefore, in many cases, sublimation can be treated as developing to the vacuum. So, the composition of ices and their actual temperature are essential factors determining sublimation intensity. The most typical and the less volatile is water ice. Solid nitrogen and carbon monoxide belong to the most volatile ices that were detected in the Solar System bodies. Fray and Schmitt (2009) present an excellent review of sublimation properties of many ices of the astrophysical interest. In Table 1 there are collected the densities, the triple point data, the critical parameters, and the latent heat of sublimation of selected ices-forming compounds the most abounded and therefore the most important for planetary sciences.

Table 2 presents the list of the ices detected on the surfaces of the satellites and on the surfaces of the KBOs. Hydrated and hydroxylated materials detected on the surfaces are mentioned as well. For data concerning relative abundances of some cometary volatiles and for solar distances where sublimation of these ices begins - see Table 3. Apart from the icy satellites, 
Table 1

Physical properties of selected ices-forming compounds

\begin{tabular}{|c|c|c|c|c|c|c|}
\hline \multirow{2}{*}{$\begin{array}{l}\text { Com- } \\
\text { pound }\end{array}$} & \multirow{2}{*}{$\begin{array}{c}\text { Density of solid } \\
\text { at pressure } 10^{5} \mathrm{~Pa} \\
\text { (at given temperature) } \\
{\left[\mathrm{kg} \mathrm{m}^{-3}\right]}\end{array}$} & \multicolumn{2}{|c|}{ Triple point* } & \multicolumn{2}{|c|}{ Critical point } & \multirow{2}{*}{$\begin{array}{c}\text { Latent } \\
\text { heat of } \\
\text { sublimation } \\
{\left[10^{5} \mathrm{~J} \mathrm{~kg}^{-1}\right]}\end{array}$} \\
\hline & & $\begin{array}{c}P \\
{[\mathrm{~Pa}]}\end{array}$ & $\begin{array}{c}T \\
{[\mathrm{~K}]} \\
\end{array}$ & $\begin{array}{c}p \\
{[\mathrm{MPa}]}\end{array}$ & $\begin{array}{c}T \\
{[\mathrm{~K}]}\end{array}$ & \\
\hline $\begin{array}{c}\mathrm{H}_{2} \mathrm{O}, \\
\text { hexagonal }\end{array}$ & $\begin{array}{l}918(\text { at } 273 \mathrm{~K}) \\
940(\text { at } 150 \mathrm{~K})\end{array}$ & 611.6 & 273.16 & 22.06 & 647 & 25.90 \\
\hline $\mathrm{CO}_{2}$ & 1640 (at $195 \mathrm{~K}$ ) & $5.185 \times 10^{5}$ & 216.60 & 7.40 & 304 & 7.58 \\
\hline $\mathrm{CO}$ & 920 (at $65 \mathrm{~K}$ ) & 15.37 & 68.10 & 3.55 & 134 & 2.16 \\
\hline $\mathrm{N}_{2}$ & 1026 (at $21 \mathrm{~K}$ ) & $1.255 \times 10^{4}$ & 63.20 & 3.39 & 136 & 2.00 \\
\hline $\mathrm{CH}_{4}$ & $\begin{array}{c}524 \text { to } 494 \\
(11 \text { to } 70 \mathrm{~K}) \\
\end{array}$ & $1.275 \times 10^{5}$ & 88.70 & 4.60 & 191 & 7.60 \\
\hline $\mathrm{NH}_{3}$ & 817 (at $193 \mathrm{~K}$ ) & 6090 & 195.49 & 11.30 & 405 & 13.70 \\
\hline $\mathrm{SO}_{2}$ & & 1670 & 187.57 & 7.87 & 430 & \\
\hline $\mathrm{C}_{2} \mathrm{H}_{4}$ & 701 & & & & & \\
\hline
\end{tabular}

*)according to Fray and Schmitt (2009)

cometary nuclei, and KBOs, the ices are present or they could be present on the rocky bodies - the terrestrial planets, the rocky moons, and the asteroids. First of all it should be noted that the water ice covers important fractions of the surface in the polar regions of the Earth. It is also present in the permafrost. Water ice was recently discovered on an asteroid Themis (Campins et al. 2010, Rivkin and Emery 2010). Presence of water ice on other asteroids is very possible as well (e.g., Hsieh 2010; recent NASA data concerning results of Dawn mission encounter with asteroid Vesta 2011). Presence of water ice is also possible on permanently shadowed regions of the Moon. Vasavada et al. (1999) considered thermal conditions required for the existence of permafrost. Crotts (2011) gives an excellent review concerning searching of water ice on the Moon; see references herein. In particular, he described cratering experiment on the Moon performed by mission LCROSS (Lunar CRater Observation and Sensing Satellite) that discovered $\mathrm{H}_{2} \mathrm{O}$ as well as $\mathrm{CO}$ originated from impacted lunar regolith. Presence of water ice on Mercury is also studied. Moses et al. (1999) considered delivering of ice onto Mercury from external sources. NASA Messenger Mercury Orbiter observations performed in 2011 provide strong arguments for the presence of water in the permanently shadowed floors of craters situated in the polar regions of Mercury. Polar caps of Mars are formed from a few meter thick layers of carbon dioxide ice; beneath it, the thick layer of water ice is expected. Evidences for water ice containing permafrost on Mars out of its 
Ices and some minerals detected on the surfaces

of the icy satellites and on the KBOs

\begin{tabular}{|c|c|}
\hline Body & Ices and other surface materials \\
\hline \multicolumn{2}{|r|}{ Jovian satellites } \\
\hline Io & $\mathrm{SO}_{2}, \mathrm{SO}_{3}, \mathrm{H}_{2} \mathrm{~S} ?, \mathrm{H}_{2} \mathrm{O}$ ? - the volcanic deposits \\
\hline Europa & $\begin{array}{l}\mathrm{H}_{2} \mathrm{O}, \mathrm{SO}_{2}, \mathrm{SH}, \mathrm{CH}, \mathrm{X} \equiv \mathrm{CN} \text {, } \\
\text { hydrous sulfate and carbonate salts, } \mathrm{H}_{2} \mathrm{O}_{2}, \mathrm{H}_{2} \mathrm{SO}_{4}, \mathrm{CO}_{2}, \mathrm{O}_{2}\end{array}$ \\
\hline Ganymede & $\begin{array}{l}\mathrm{H}_{2} \mathrm{O}, \mathrm{SO}_{2}, \mathrm{SH}, \mathrm{CH}, \mathrm{X} \equiv \mathrm{CN} \\
\text { hydrated and hydroxylated minerals, } \mathrm{O}_{2}, \mathrm{O}_{3} \mathrm{CO}_{2}\end{array}$ \\
\hline Callisto & $\begin{array}{l}\mathrm{H}_{2} \mathrm{O}, \mathrm{SO}_{2}, \mathrm{SH}, \mathrm{CH}, \mathrm{X} \equiv \mathrm{CN} \\
\text { hydrated and hydroxylated minerals, } \mathrm{CO}_{2}\end{array}$ \\
\hline \multicolumn{2}{|r|}{ Saturnian system } \\
\hline Rings & $\mathrm{H}_{2} \mathrm{O}$ \\
\hline Mimas & $\mathrm{H}_{2} \mathrm{O}$ \\
\hline Enceladus & $\mathrm{H}_{2} \mathrm{O}$ and $\mathrm{NH}_{3}$ forming the hydrates $\left(\mathrm{H}_{2} \mathrm{O}\right)_{\mathrm{x}}\left(\mathrm{NH}_{3}\right)_{1-\mathrm{x}}$ \\
\hline Tethys & $\mathrm{H}_{2} \mathrm{O}$ \\
\hline Dione & $\mathrm{H}_{2} \mathrm{O}, \mathrm{C}, \mathrm{HC}, \mathrm{O}_{3}$ \\
\hline Rhea & $\mathrm{H}_{2} \mathrm{O}, \mathrm{HC} ?, \mathrm{O}_{3}$ \\
\hline Hyperion & $\mathrm{H}_{2} \mathrm{O}$ \\
\hline Iapetus & $\mathrm{H}_{2} \mathrm{O}, \mathrm{C}, \mathrm{HC}, \mathrm{H}_{2} \mathrm{~S}$ \\
\hline Phoebe & $\mathrm{H}_{2} \mathrm{O}$ \\
\hline Titan & Hydrocarbons lakes or oceans (Cassini-Huygens data) \\
\hline \multicolumn{2}{|r|}{ Uranian satellites } \\
\hline Miranda & $\begin{array}{l}\mathrm{H}_{2} \mathrm{O} \text { and } \mathrm{NH}_{3} \text { forming the hydrates }\left(\mathrm{H}_{2} \mathrm{O}\right)_{\mathrm{x}}\left(\mathrm{NH}_{3}\right)_{1-\mathrm{x}} \text {, } \\
\text { hydroxylated silicates }\end{array}$ \\
\hline Ariel & $\mathrm{H}_{2} \mathrm{O}, \mathrm{OH} ?$ \\
\hline Umbriel & $\mathrm{H}_{2} \mathrm{O}$ \\
\hline Titania & $\mathrm{H}_{2} \mathrm{O}, \mathrm{C}, \mathrm{HC}, \mathrm{OH}$ ? \\
\hline Oberon & $\mathrm{H}_{2} \mathrm{O}, \mathrm{C}, \mathrm{HC}, \mathrm{OH}$ ? \\
\hline $\begin{array}{l}\text { Neptunian } \\
\text { satellite Triton }\end{array}$ & $\mathrm{N}_{2}, \mathrm{CH}_{4}, \mathrm{CO}, \mathrm{CO}_{2}, \mathrm{H}_{2} \mathrm{O}$ \\
\hline Pluto and Charon & $\mathrm{N}_{2}, \mathrm{CH}_{4}, \mathrm{CO}, \mathrm{H}_{2} \mathrm{O}$ and $\mathrm{NH}_{3}$ forming the hydrates $\left(\mathrm{H}_{2} \mathrm{O}\right)_{\mathrm{x}}\left(\mathrm{NH}_{3}\right)_{1-\mathrm{x}}$ \\
\hline KBOs & $\mathrm{H}_{2} \mathrm{O}, \mathrm{HC}$ ices $\left(\right.$ e.g., $\left.\mathrm{CH}_{4}, \mathrm{CH}_{3} \mathrm{OH}\right)$, silicates, $\mathrm{NH}_{3}$, and $\mathrm{C}_{2} \mathrm{H}_{6}$ \\
\hline
\end{tabular}

Note: according to Roush (2001), updated: http://science.gsfc.nasa.gov/691/ cosmicice/sol-sys.html (2012) 
Table 3

Cometary ices' composition by number of molecules relative to water, distance $r$ from the Sun of the onset of vaporization of the given molecules, the temperature $T=278.3 r^{-1 / 2}$ of the fast and chaotic rotating blackbody at the solar distance $r$, and the region of the Solar System where this temperature is reached

\begin{tabular}{|l|c|c|c|l|}
\hline \multicolumn{1}{|c|}{ Molecule } & $\begin{array}{c}\text { Abundance } \\
\text { in comets } \\
\mathrm{H}_{2} \mathrm{O}=100^{*}\end{array}$ & $\begin{array}{c}r \\
{[\mathrm{AU}]}\end{array}$ & $\begin{array}{c}T \\
{[\mathrm{~K}]}\end{array}$ & \multicolumn{1}{|c|}{ Region } \\
\hline Nitrogen, $\mathrm{N}_{2}$ & & 77.6 & 32 & Kuiper belt \\
\hline Carbon monoxide, $\mathrm{CO}$ & $1.8-30$ & 62.5 & 35 & \\
\hline Methane, $\mathrm{CH}_{4}$ & $0.14-1.5$ & 38.0 & 45 & $\begin{array}{l}\text { Kuiper belt inner } \\
\text { boundary }\end{array}$ \\
\hline Formaldehyde, $\mathrm{CH}_{2} \mathrm{O}$ & $0.13-1.3$ & 14.1 & 74 & \\
\hline Ammonia, $\mathrm{NH}_{3}$ & $0.2-1.0^{* *}$ & 9.7 & 89 & $\begin{array}{l}\text { Saturn system solar } \\
\text { distance }\end{array}$ \\
\hline Carbon dioxide, $\mathrm{CO}_{2}$ & $3-6$ & 8.3 & 97 & \\
\hline Sulfur dioxide, $\mathrm{SO}_{2}$ & $0.2(\mathrm{Hale}-\mathrm{Bopp})$ & 5.2 & 108 & $\begin{array}{l}\text { Jupiter system solar } \\
\text { distance }\end{array}$ \\
\hline $\begin{array}{l}\text { Hydrogen cyanide, } \\
\mathrm{HCN}\end{array}$ & $0.02-0.25$ & 4.8 & 127 & \\
\hline $\begin{array}{l}\text { Ammonia, } \mathrm{NH}_{3} \text { from } \\
\left(\mathrm{H}{ }_{2} \mathrm{O}\right)_{\mathrm{x}}\left(\mathrm{NH}_{3}\right)_{1-\mathrm{x}} \text { system }\end{array}$ & & 2.6 & 172.6 & $\begin{array}{l}\text { Asteroid main belt } \\
\text { inner boundary }\end{array}$ \\
\hline Water, $\mathrm{H}_{2} \mathrm{O}$ & 100 & 2.5 & 176.0 & $\begin{array}{l}\text { Comets approaching } \\
\text { the Sun }\end{array}$ \\
\hline
\end{tabular}

Notes: Composition data are dispersed in large intervals: they varied from a comet to a comet and "the mean typical composition" given in different sources differs considerably.

*) Based on Bockeleé-Morvan et al. (2004).

${ }^{* *}$ Taking into account the relative abundance oxygen/nitrogen $\approx 1 / 7$ in the solar nebula one get the maximum value of water/ammonia ratio $\sim 14 \%$, provided that all nitrogen is linked with hydrogen forming ammonia.

polar regions are intensively searched (e.g., Richardson and Wilson 2002, Byrne et al. 2009).

\section{ICES AT LOW TEMPERATURE AND CLATHRATES}

The water ice is less volatile and most abundant of all ices of interest for planetary sciences. There are no doubts that water ice is the main component of the Solar System ices, at least on surfaces or just beneath the surfaces of the icy objects, see Table 2. Physical properties of water ice in large intervals 
of pressure and temperature are the subjects of intense laboratory searches for more than a century. It has been found that there are 18 polymorphic phases of crystalline water ice as well as 3 forms of amorphous ice with different density (Zheligovskaya and Malenkov 2006). At near-zero pressure conditions, i.e., on the surfaces of the Solar System bodies and inside of the smallest of them (cometary nuclei), the amorphous ice and the crystalline ice in hexagonal form are expected.

For the laboratory studies of non-water ices, the presence of ubiquitous water molecules in the investigated icy material is sometimes harmful for interpretation of experimental results. The systems of water plus a highly volatile material usually present complex phase diagrams. These diagrams depend on three variables at least: temperature, pressure, and concentration (concentrations) of the highly volatile component (components). For the goal of planetary surface sciences, the phase diagrams at one bar pressure are sufficiently precise for many studies. Figure 1 presents phase diagram of water-ammonia system at 1 bar as well as in the waste range of pressure. Both of them could be interesting for surfaces' physics and for studies of the interiors of the icy bodies (e.g., Enceladus), respectively.

The gases forming ices other than the water ice are admixtures, whose total molecular abundance relative to water is no greater than a dozen or so, see Table 3. These admixtures, if considered individually, are much more volatile than the water ice. The highly volatile molecules of different nonwater ice-forming compounds can be trapped in low temperatures into solid water forming the clathrates. However, the molecules that are built-in into the water ice structure remain trapped even in much higher temperatures than their proper sublimation temperature. Highly volatile molecules are releasing from the water ice structure when temperature increases sufficiently. Studies of clathrates in application to planetary sciences are performed by many authors. Some representative papers are cited in the following. They are divided in two groups that are related to pressure conditions:

口 The clathrate studies at elevated pressures (at interiors conditions). Lunine and Stevenson (1987) considered clathrate and ammonia hydrates at high pressures in the interior of Titan. Hand et al. (2006) considered the possibility of formation of carbon dioxide and sulfur dioxide clathrates under the surface of Europa. Fortes and Choukroun (2010) describe the high pressure phase behavior of clathrates of methane and ammonia.

- The clathrate studies at very low pressures (at surfaces conditions as well as inside cometary nuclei). Hersant et al. (2004) considered composition of the giant planets under the assumption that volatiles were trapped in the form of solid clathrate hydrates and incorporated in planetesimals embedded in the feeding zones of each of the four giant planets. Jewitt et 

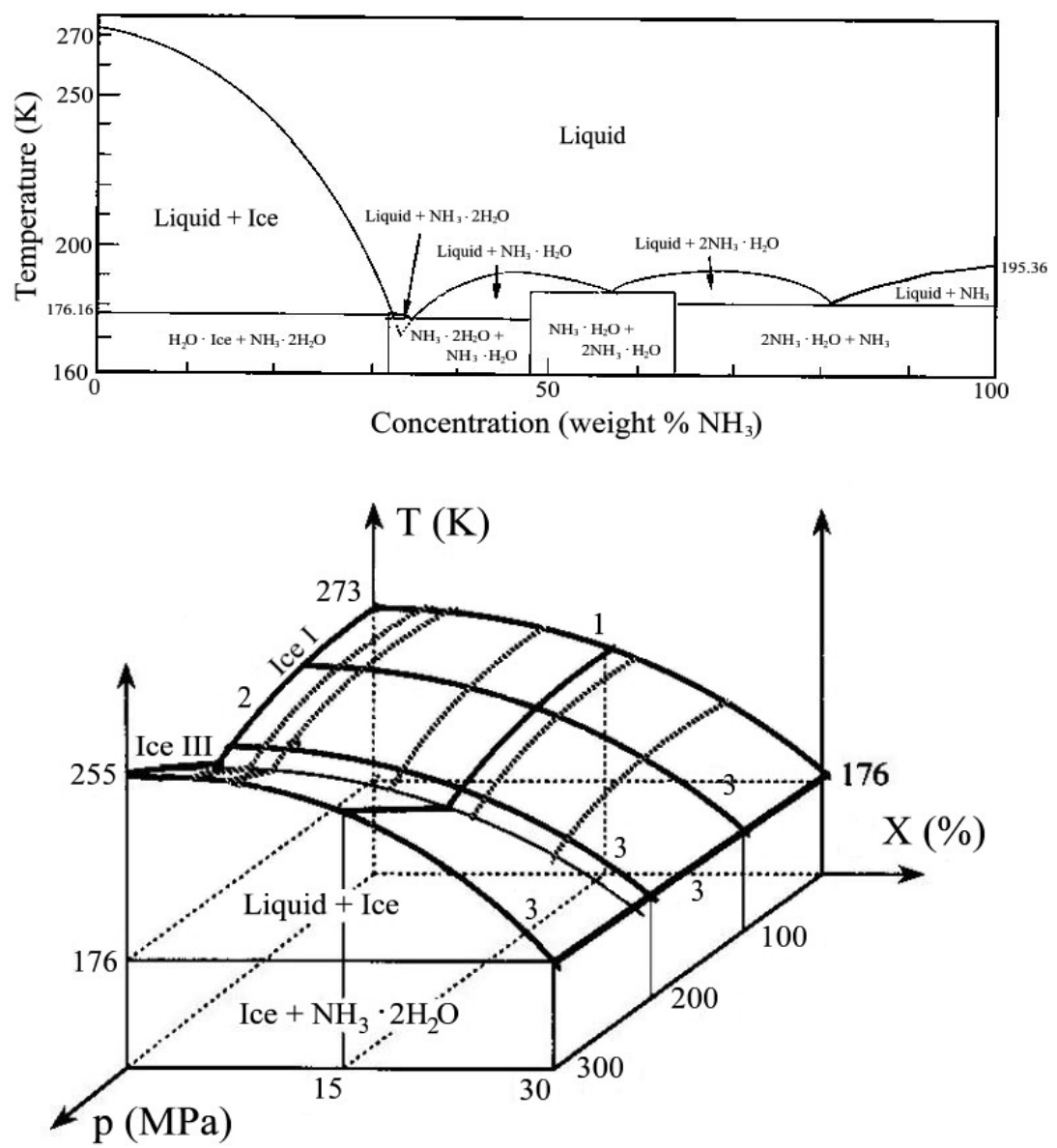

Fig. 1. Phase diagrams of water-ammonia system at atmospheric pressure (top) and at high pressure (bottom). Curve 1 is the melting curve of $\mathrm{H}_{2} \mathrm{O} \cdot \mathrm{NH}_{3}$ at $0.1 \mathrm{MPa}$. Curve 2 is the melting curve of pure $\mathrm{H}_{2} \mathrm{O}$. Label 3 relates to literature data at isobaric conditions. Dashed thick lines are the results of Leliwa-Kopystyński et al. (2002).

al. (2008) and Gronkowski and Sacharczuk (2010) stated that carbon monoxide might be physically trapped within a porous, amorphous ice matrix and released where the local temperatures are sufficient to promote the transformation of amorphous into crystalline ice. Marboeuf et al. (2010) discuss susceptibility of formation of the so-called multiple guest clathrate due to presence of several volatile compounds in the gas phase of the porous network of the cometary nuclei. Gronkowski et al. (2011) discuss the carbon dioxide geysers from the nucleus of comet 103P/Hartley 2. 
Traces of water are always present in the experimental system. Water is ubiquitous in all icy bodies of the Solar System. However, in the temperature range of experiments performed in this work, practically all water molecules are frozen within the system and thus they are not involved into observations. An analogy to the observation data concerning outgasing of the distant bodies of the Solar System is clearly visible. Degassing of water molecules from the cometary nuclei is observed when the comets are approaching the Sun and the nuclei temperature exceeds about $100 \mathrm{~K}$. Sublimation of the water molecules from the surfaces of the icy moons of the giant planets is not observed. Water vapor jets from Enceladus are originated from the subsurface sources.

\section{EXPERIMENTAL SET-UP}

We have studied sublimation processes from a thin layer of ice. The scheme of experimental system is presented and described in Fig. 2. The ice was deposited from gas on a thin circular gold plate of the Quartz Cristal MicroBalance (QCMB) with a diameter of about $1 \mathrm{~cm}$ at vacuum conditions at a cold chamber. Changing mass of ice depositing on or evaporating from the QCMB changes its vibration frequency. Pressures in the chamber with QCMB as well as temperature of cold finger were continuously monitored. Experimental possibilities allow performing measurements of the timedependent variations of the following:

口 Fluxes of different ions from the subliming layer. Multichannel mass spectrometer was applied. These measurements were essential for this paper.

口 Thickness of the deposited ice by means of laser interferometry.

- Porosity and density of the deposited ice.

- Optical parameters (refraction index and absorption index) of the thin layer of the deposited ices.

The cryosystem with temperature regulation allowed introducing different programs of changes of temperature of the cold finger. The experiment started from cooling and pumping down the system. After stabilization of temperature at its lowest value (about $10 \mathrm{~K}$ ), the required gas or the mixture of gases fills up the cold chamber and deposition of ice starts. When the required thickness of the ice layer is reached, the temperature begins to increase following appropriate program. We have looked for an onset of degassing of different molecules and for maxima of their degassing rate versus temperature. Continuous or step-like program of increasing of temperature was used. The typical increasing rate was a continuous growth of temperature $1 \mathrm{~K}$ per 1 minute. Thus, the duration of one experimental run was about three hours. 


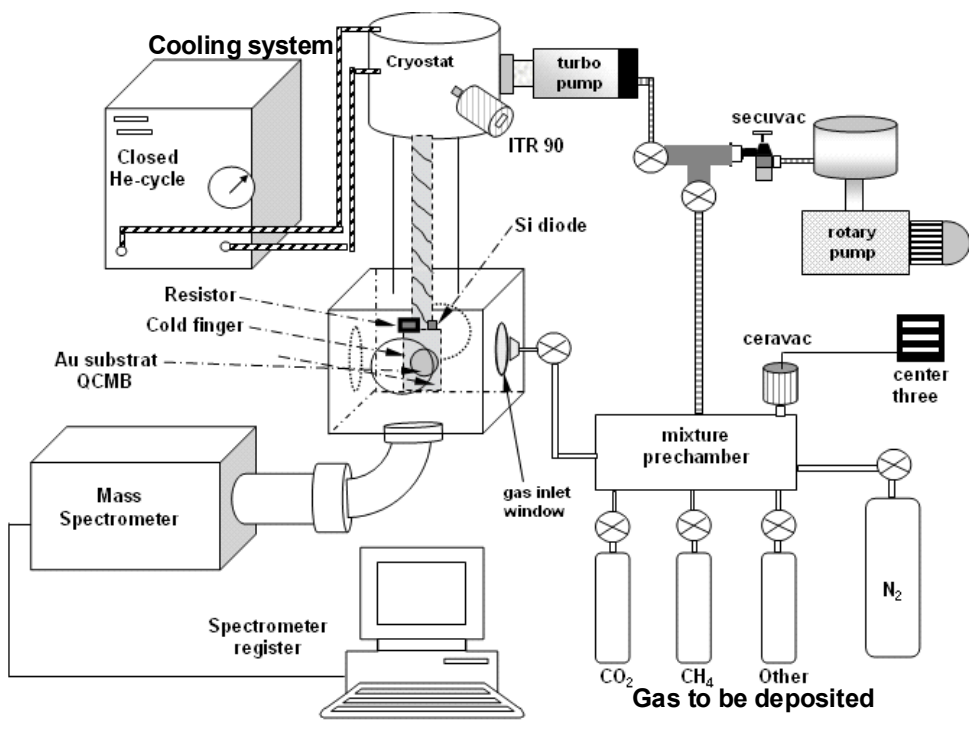

Fig. 2. Scheme of experimental system used for studying sublimation of ices (described by Luna et al. 2008): (1) Helium closed system cooling the cryostat; (2) Vacuum system: Rotary pump followed by turbo molecular pump; (3) The system that supplies gas for deposition to the cold chamber. Gas of required composition is mixed in the pre-chamber; (4) The cold chamber with QCMB. Nominal pressure range in the chamber is $\left(10^{-9}-10^{-5}\right)$ mbar. Temperature of the cold finger in a center of the chamber is $15-110 \mathrm{~K}$. The external walls of the chamber remain at room temperature; (5) The mass spectrometer to follow the intensity of sublimation of the individual components of subliming material. Six components can be followed at once; (6) The two laser system for measurement by reflection interferometry the actual thickness (variable with time) of depositing or subliming ice layer; (7) The heating system, not visible on this scheme. Different regimes of heating rate [K per minute] of the cold finger can be used. The devices from (1) to (5) are described on the scheme. So, they are well distinguishable. Devices (6) and (7) are not presented on the scheme.

\section{RESULTS AND CONCLUSIONS}

In Figure 3, the scheme of changes of frequency of QCMB versus time of experiment is presented. These changes are related to two effects. They are the mass changes of vibrating plate of QCMB and the temperature dependence of vibration frequency. First of all, they result from the changing mass of ice deposited on the vibrating plate of QCMB. During deposition (sublimation) the mass of QCMB increases (decreases) and therefore its frequency decreases (increases). The frequency decreases (increases) almost proportionally to increasing (decreasing) mass of the vibrating plate. The word "almost" stands for underlying that the temperature depending correction 


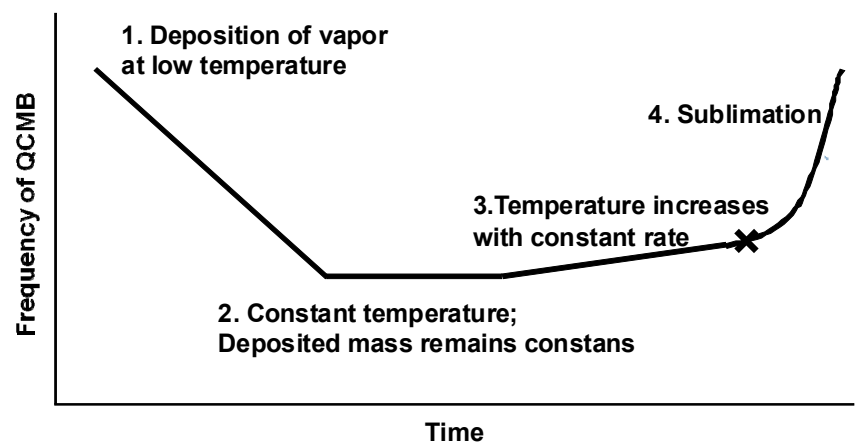

Fig. 3. Scheme of changes of frequency of QCMB versus time of experiment. Consecutive stages of experiments are: 1. Leftmost straight segment slopping down: mass is deposited at constant temperature (about $15 \mathrm{~K}$ ) from the gas at constant pressure. So, deposition rate is constant, and frequency of QCMB decreases with constant rate as well; 2. Horizontal segment: Mass of deposited material is kept constant at low temperature (about $15 \mathrm{~K}$ ) and at low pressure. Therefore, there is neither deposition nor sublimation; 3. Rightmost straight segment: Temperature increases with constant rate; 4 . Sublimation starts at certain moment $(\times)$. This is observed as a change of frequency of CQMB and verified by means of mass spectrometer.

must be introduced. The frequency versus temperature calibration of QCMB at a constant mass of vibrating plate is done before experiments.

Results of experiments are gathered in Tables 4 and 5. Table 4 lists the sublimation maxima from the icy system $\mathrm{N}_{2} \& \mathrm{NH}_{3}$. The nitrogen to ammonia mixing ratio is regulated by an appropriate choice of pressure of individual components in the gas mixing chamber. This ratio was 8.5:57, 32.75:32.75, and 57:57 in different runs; here the numerals denote partial pressure in milibars. Three runs of those presented in Table 4 are illustrated in Fig. 4a-d. Individual panels of this figure are the raw results gathered from two experimental runs (Fig. 4a, d) or from two parts of one run (Fig. 4b, c). The four panels of Fig. 4 present sublimation (outgasing) versus time and therefore versus temperature, since the temperature increase rate was constant. Time in seconds is marked on the horizontal axis. The black smoothly increasing line presents the laser record that allows to follow changes of the thickness of the deposited ice layer. This line is going up with increasing temperature. The straight vertical segments going down from this line are the parasite pulses originated from short-duration losses of laser signal. Fortunately, these losses of signal have only very minor influence on completeness of the collection of the experimental results. The temperature in Kelvin is marked on the right vertical axis. The records of temperature are given by straight lines going up across the panel from the left to the right. 


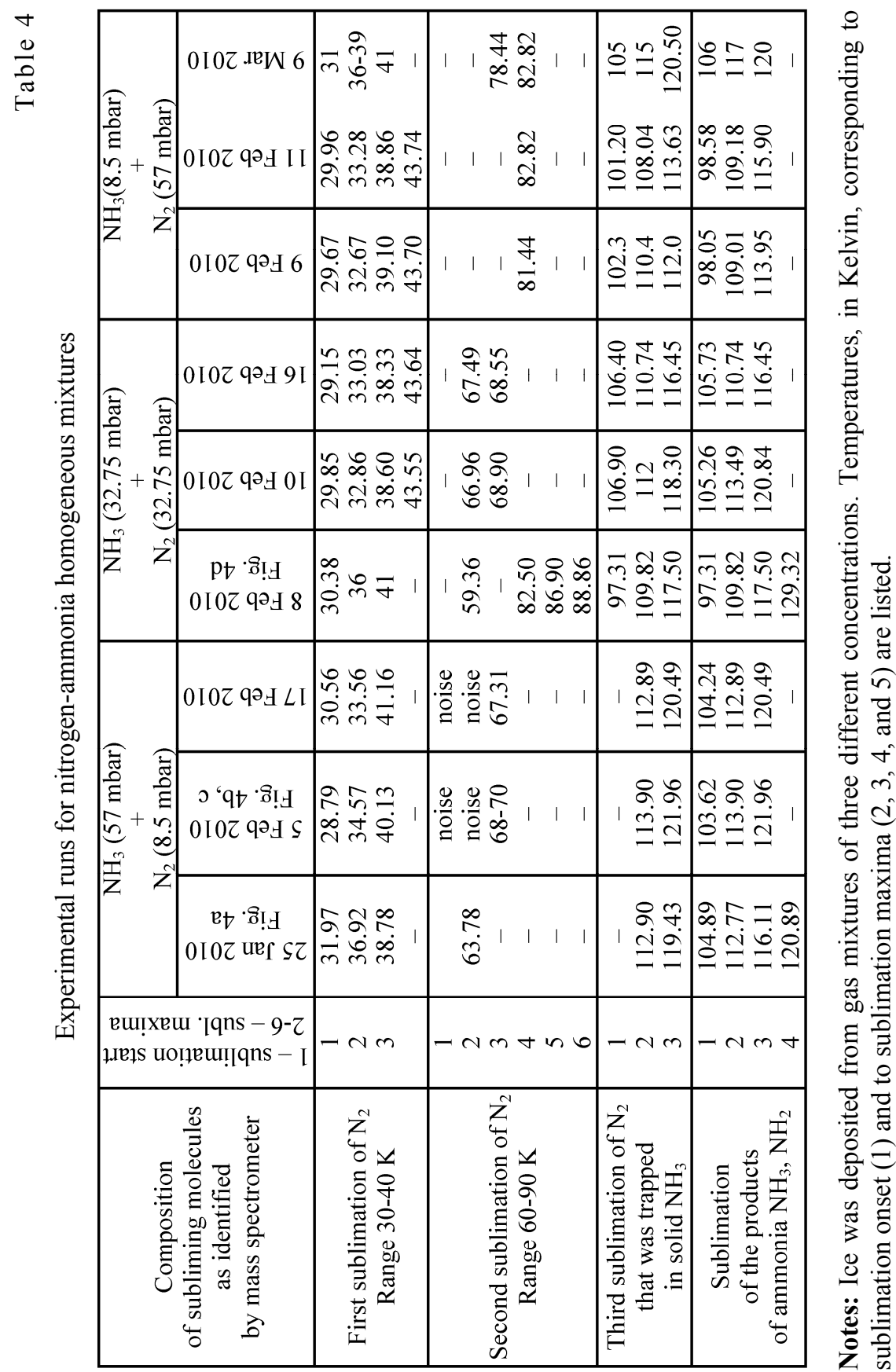


$\frac{1}{5}$

\begin{tabular}{|c|c|c|c|c|c|}
\hline \multirow{4}{*}{ 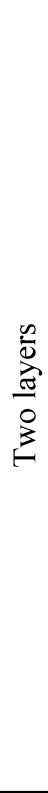 } & 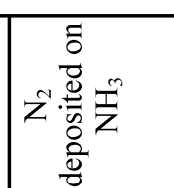 & 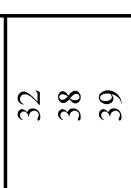 & 8 ชิ 1 & $\stackrel{\varrho}{=}$ & \&े § 1 \\
\hline & 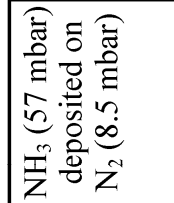 & ले ले & $\stackrel{+}{+} \underset{n}{i} \overline{0} 1$ & $\stackrel{n}{\stackrel{n}{=}} \cong$ & 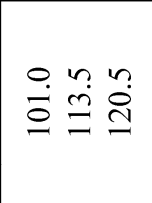 \\
\hline & 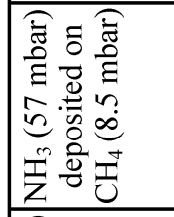 & $\frac{n}{q} \frac{n}{\frac{n}{\gamma}}$ & 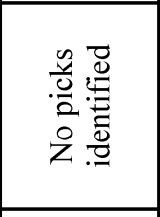 & $\stackrel{\sigma}{0} \stackrel{ }{=}$ & $\stackrel{\sigma}{\varrho} \cong \bar{\beth}$ \\
\hline & 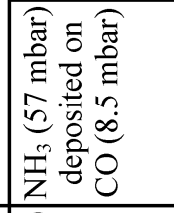 & ìn & 851 & 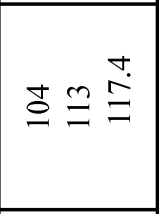 & $\stackrel{ }{=} \cong$ \\
\hline \multirow{3}{*}{ 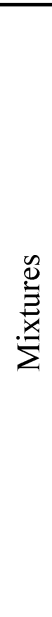 } & 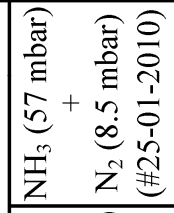 & ले ले के & ర్ర t్ర 1 & $\stackrel{2}{=} \cong$ & $\stackrel{\stackrel{0}{=}}{\stackrel{1}{=}}$ \\
\hline & 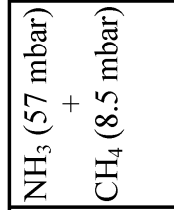 & $F \stackrel{f}{q}$ & 868 & $8 \stackrel{2}{=}$ & ○ \\
\hline & 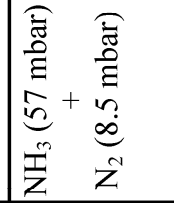 & 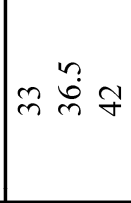 & r & $\hat{\varrho} \equiv 1$ & 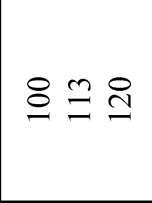 \\
\hline \multicolumn{2}{|c|}{ 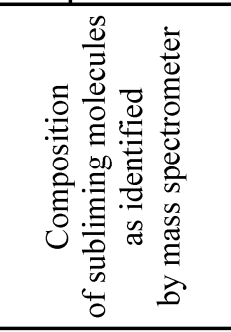 } & 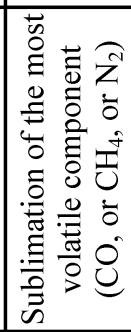 & 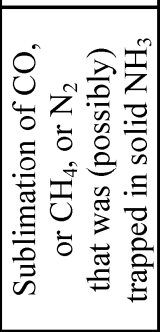 & 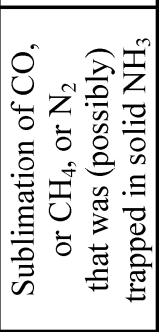 & 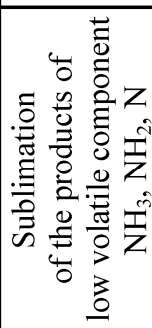 \\
\hline
\end{tabular}


The left-hand side vertical axis is for frequency of the QCMB, in hertz. The most right-hand scale is for pressure in the chamber, in milibars. When the temperature increases, the pressure varies importantly, following the intensity of sublimation. The records of mass spectrometer are calibrated for the

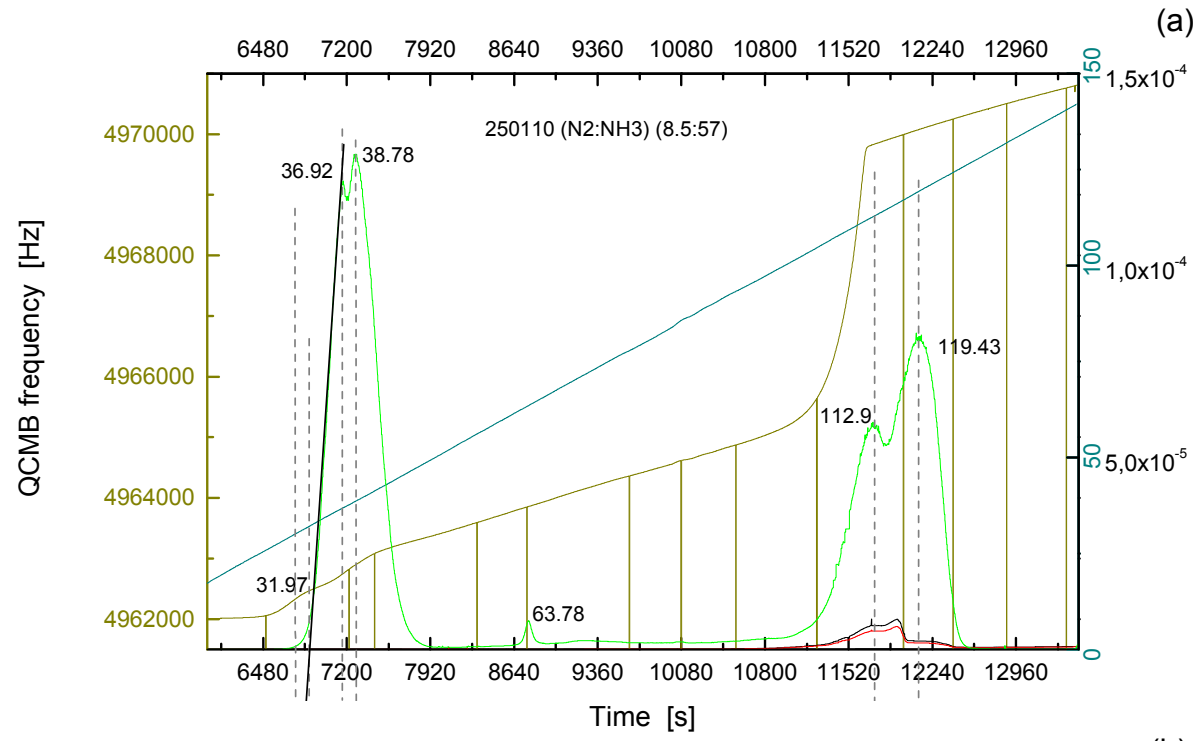

(b)

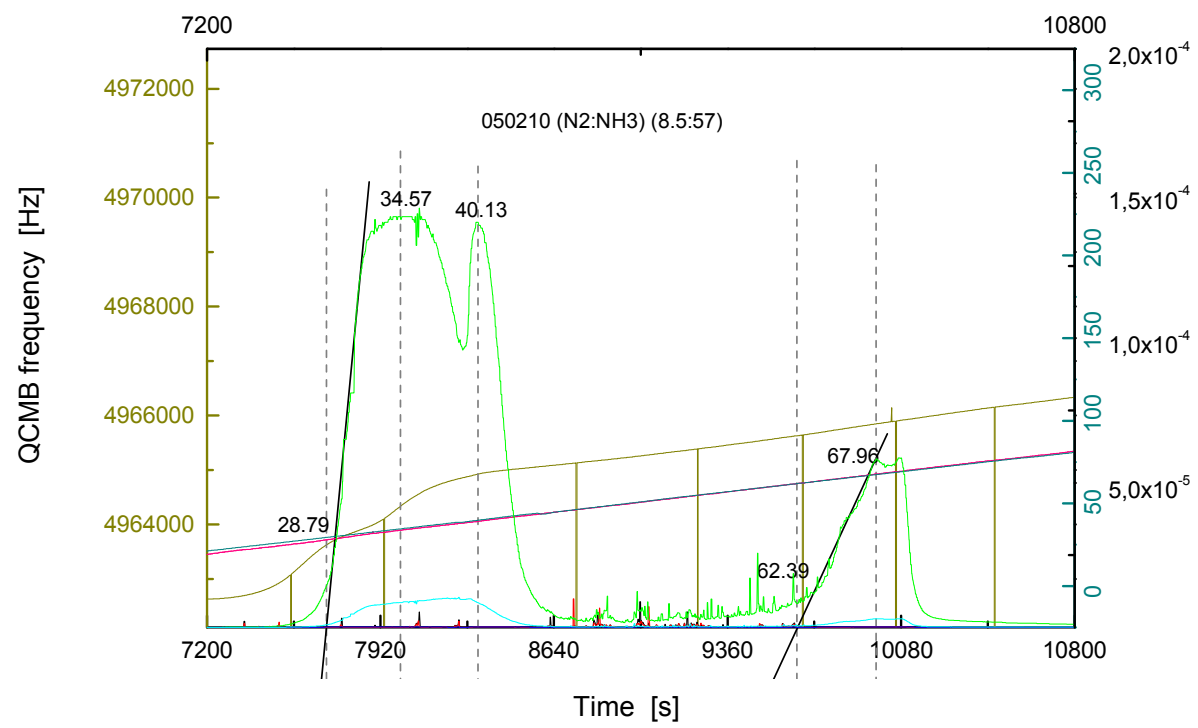

Fig. 4. Continued on next page. 


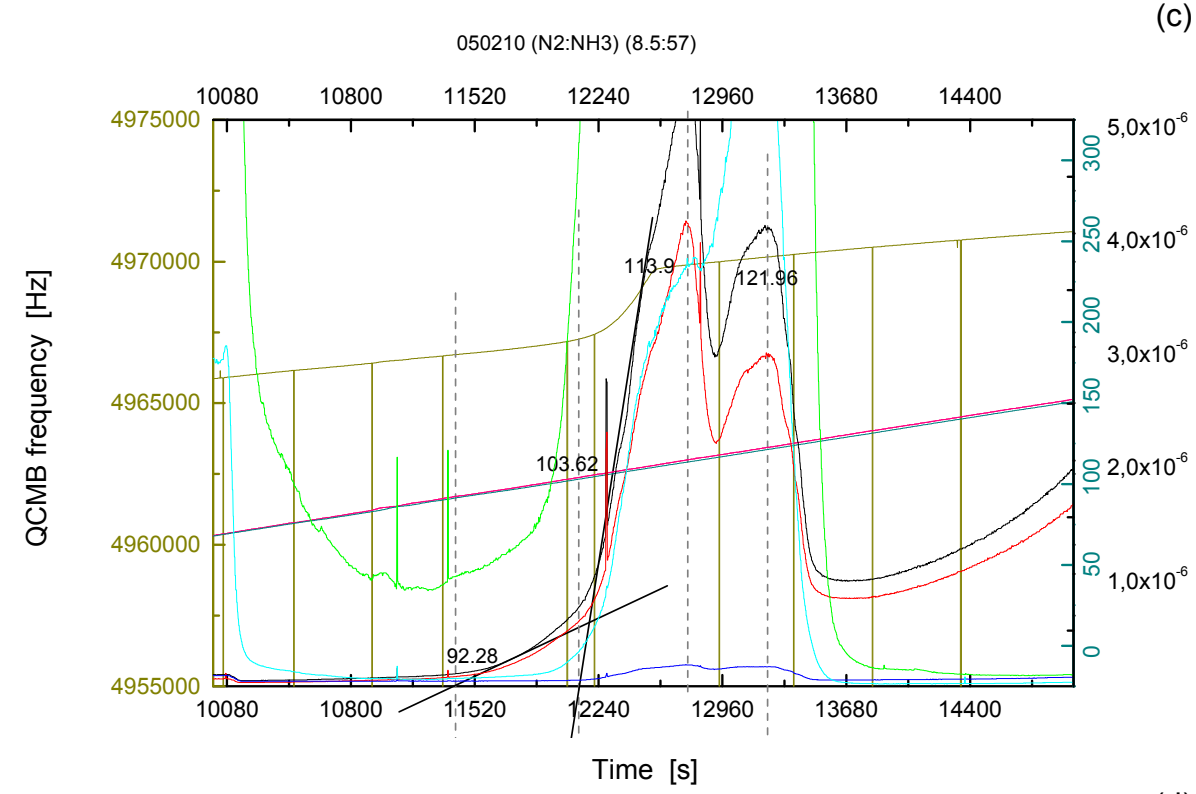

(c)

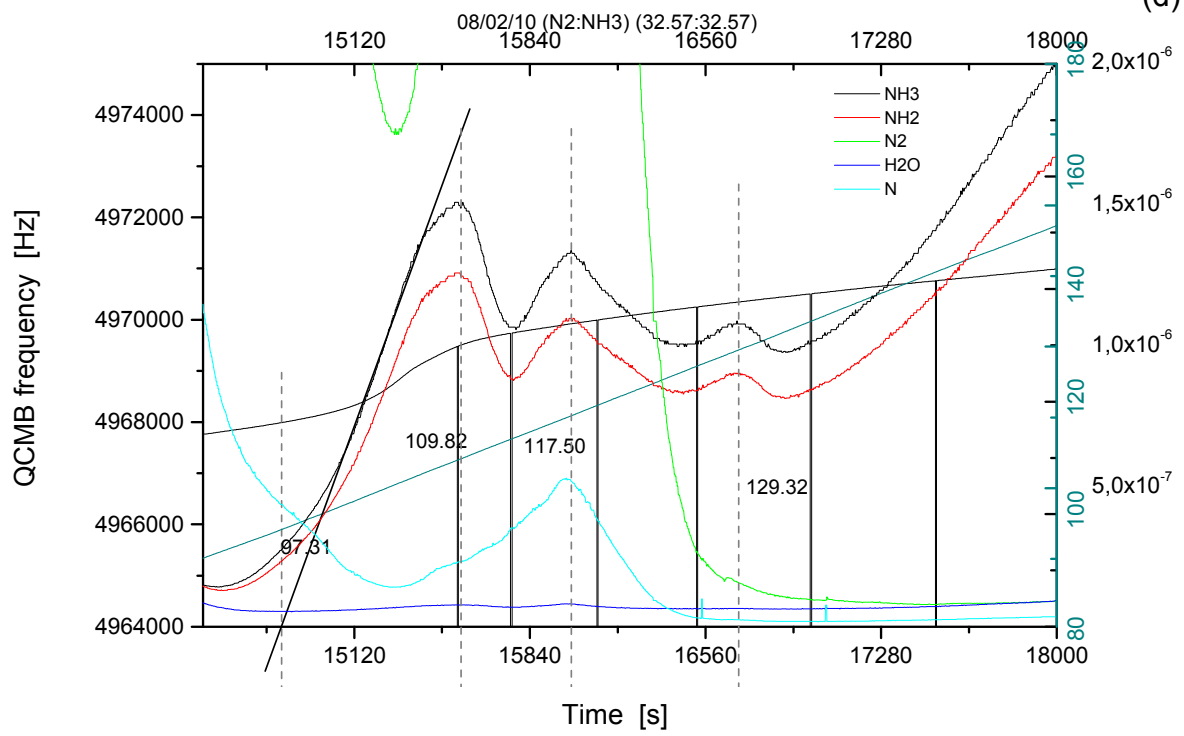

Fig. 4. The plots of data obtained in three experimental runs. See Table 5 and follow the text when watching the figures: (a) Run 25 Jan 2010. Full range of temperature $20=140 \mathrm{~K}$; (b) Run 5 Feb 2010 (part 1). Temperature range 20-80 K. Two distinct regions of nitrogen sublimation are clearly visible; (c) Run 5 Feb 2010 (part 2). Temperature range 80-150 K. Ammonia-products $\left(\mathrm{NH}_{3}\right.$ and $\left.\mathrm{NH}_{2}\right)$ sublimation region; (d) Run 8 Feb 2010. Temperature range 80-150 K. Ammonia-products $\left(\mathrm{NH}_{3}\right.$ and $\mathrm{NH}_{2}$ ) sublimation region. Colour version of this figure is available in electronic edition only. 
partial pressure of five ions. These records are continuously registered and they are presented as colored lines: $\mathrm{NH}_{3}$ black, $\mathrm{NH}_{2}$ red, $\mathrm{N}_{2}$ green, $\mathrm{H}_{2} \mathrm{O}$ dark blue, and $\mathrm{N}$ light blue. The pikes on these lines are marked by vertical dashed lines. Some of the pikes are described by temperatures corresponding to them.

In Table 4 there are listed the temperatures corresponding to sublimation peak of different ions that are escaping from the homogeneous nitrogenammonia icy systems of three different molecular ratios $\mathrm{N}_{2}: \mathrm{NH}_{3}$. Usually the temperature regions where intense sublimation occurs have double, triple, or even more complex structure spanning over a few Kelvin or more. The onset of primary sublimation of nitrogen is observed at $31 \pm 2 \mathrm{~K}$, and its doublepeak maximum is at $38 \pm 3 \mathrm{~K}$. At the interval of temperature from about 40 to about $60 \mathrm{~K}$ sublimation is almost negligible. Next, the secondary sublimation of nitrogen develops in the region $64-70 \mathrm{~K}$ (for $\mathrm{N}_{2}: \mathrm{NH}_{3}=8.5: 57$ ). However, for higher concentration of nitrogen the sublimation pattern changes. For $\mathrm{N}_{2}: \mathrm{NH}_{3}=32.75: 32.75$ and for $\mathrm{N}_{2}: \mathrm{NH}_{3}=57: 8.5$ an intense sublimation of nitrogen appears at the temperature $82 \mathrm{~K}$. In all nine experiments presented in Table 4 the third (and the last) nitrogen degassing process develops at the interval $105-120 \mathrm{~K}$. In the same region of temperature, there is observed sublimation of ammonia $\mathrm{NH}_{3}$ and the ammonia-originated ions $\mathrm{NH}_{2}$. Tripple peak structure of maximum sublimation of these ions is observed. Temperature that corresponds to the peak in the middle exactly correlates with the very intense peak of molecular nitrogen $\mathrm{N}_{2}$ and with much weeker peak of atomic nitrogen N, see Fig. 4d. We cannot definitively distinguish the origin of the atomic nitrogen: Has it originated from dissociated molecules of $\mathrm{N}_{2}$ or from disociation of molecules of ammonia? In the region $120-130 \mathrm{~K}$ there is a shallow minimum of intensity of sublimation. Next, above $130 \mathrm{~K}$, the fluxes of $\mathrm{NH}_{3}$ and $\mathrm{NH}_{2}$ increase importantly but nitrogen in the $\mathrm{N}_{2}$ and $\mathrm{N}$ forms is in the lower limit of observation possibility.

Table 5 collects results of the experimental runs where sublimation from the complex ices was studied. Samples composed of two volatiles or twolayered ice were studied. Each sample contained $\mathrm{NH}_{3}$ playing the role of a lowvolatile material. The $\mathrm{CO}$, or $\mathrm{CH}_{4}$, or $\mathrm{N}_{2}$ are the high-volatiles. The concentration $\left(\mathrm{NH}_{3}\right):\left(\mathrm{CO}\right.$, or $\mathrm{CH}_{4}$, or $\left.\mathrm{N}_{2}\right)$ was the same for each sample and it was equal to the ratio of pressure of the constituent gases, $(57 \mathrm{mbar}):(8.5 \mathrm{mbar})$. So, the amount of ammonia was 7 times larger than the amount of the highly volatile material. We have found no differences of sublimation pattern from homogeneous and from layered samples. This possibly results from the fact that the layers are enough thin and moreover they are porous. The first degassing process of the high volatiles is observed at $36-42 \mathrm{~K}$ for $\mathrm{CO}$, at 
44-51 $\mathrm{K}$ for $\mathrm{CH}_{4}$, and at 37-39 $\mathrm{K}$ for $\mathrm{N}_{2}$. The secondary sublimation of highly volatile was in the range $64-66 \mathrm{~K}$ for $\mathrm{CO}$, at $67-69 \mathrm{~K}_{\text {for }} \mathrm{CH}_{4}$, and at 61 $64 \mathrm{~K}$ for $\mathrm{N}_{2}$. The third (the last) stage of sublimation develops from above $100 \mathrm{~K}$ when ammonia sublimed.

Summarizing the experimental results for sublimation of complex ices:

- The first sublimation of highly volatile component $\left(\mathrm{CO}, \mathrm{CH}_{4}\right.$, or $\left.\mathrm{N}_{2}\right)$ develops at its proper sublimation temperature, therefore somewhere in the range of $30-50 \mathrm{~K}$.

- The second sublimation of highly volatile component develops at temperature region $60-70 \mathrm{~K}$. However, the intensity of second sublimation is less than that of the first one.

- At temperatures $100-120 \mathrm{~K}$ the highly volatile component disappears definitively. In this temperature region, intense sublimation of low volatile component (in our case $\mathrm{NH}_{3}$ ) begins to develop intensively.

Summarizing: The sublimation of constituent gases from the twocomponent ices develops at their proper sublimation temperature as well as at the temperatures different from those for sublimation of the individual components. We have checked that the high volatiles are going out from the ice $\left(\mathrm{NH}_{3}\right) \&$ (high volatile) at two or three different temperature ranges. This effect can be considered for modeling of cometary outbursts (see, e.g., Gronkowski and Sacharczuk 2010, Kossacki and Szutowicz 2011) as well as for cryovolcanic effects on the icy satellites (Enceladus, Triton) of the giant planets. Gronkowki and Sacharczuk (2010) wrote that "the stresses related to $\mathrm{CO}$ inclusions appear to be the most probable cause of the comet $17 \mathrm{P} /$ Holmes outburst". We can supplement this statement supposing that the gaseous $\mathrm{CO}$ reservoirs could be filled up by means of delivering of gaseous $\mathrm{CO}$ thermally liberated from the surrounding water \& carbon oxide ice. It would be interesting to check whether a complex ice $\left(\mathrm{H}_{2} \mathrm{O}\right)$ \& (highly volatile), e.g., the $\mathrm{H}_{2} \mathrm{O} \& \mathrm{CO}$ ice, has a similar sublimation pattern.

Acknowledgments. J. Leliwa-Kopystyński thanks Polytechnic University of Valencia, Campus of Alcoi, Department of Applied Physics, for making possible his research visit. This work was also supported by the grant No. 4036/B/H03/2010/39 provided by Polish National Center of Science.

References

Bockelée-Morvan, D., J. Crovisier, M.J. Mumma, and H.A. Weaver (2004), The composition of cometary volatiles. In: M.C. Festou, H.U. Keller, H.A. Weaver (eds.), Comets II, University of Arizona, Tucson, 391-423. 
Byrne, S., C.M. Dundas, M.R. Kennedy, M.T. Mellon, A.S. McEwen, S.C. Cull, I.J. Daubar, D.E. Shean, K.D. Seelos, S.L. Murchie, B.A. Cantor, R.E. Arvidson, K.S. Edgett, A. Reufer, N. Thomas, T.N. Harrison, L.V. Posiolova, and F.P. Seelos (2009), Distribution of mid-latitude ground ice on Mars from new impact craters, Science 325, 5948, 1674-1676, DOI: 10.1126/science. 1175307.

Campins, H., K. Hargrove, N. Pinilla-Alonso, E.S. Howell, M.S. Kelley, J. Licandro, T. Mothé-Diniz, Y. Fernandez, and J. Ziffer (2010), Water ice and organics on the surface of the asteroid 24 Themis, Nature 464, 7293, 13201321, DOI: 10.1038 /nature09029.

Crotts, A. (2011), Water on the Moon, I. Historical overview, Astron. Rev. 6, 8, 4-20.

Fortes, A.D., and M. Choukroun (2010), Phase behaviour of ices and hydrates, Space Sci. Rev. 153, 1-4, 185-218, DOI: 10.1007/s11214-010-9633-3.

Fray, N., and B. Schmitt (2009), Sublimation of ices of astrophysical interest: A bibliographic review, Planet. Space Sci. 57, 14-15, 2053-2080, DOI: 10.1016/ j.pss.2009.09.011.

Gronkowski, P., and Z. Sacharczuk (2010), Cometary outbursts - a search for a cause of the comet 17P/Holmes outburst, Mon. Not. Roy. Astron. Soc. 408, 2, 1207-1215, DOI: 10.1111/j.1365-2966.2010.17194.x.

Gronkowski, P., Z. Sacharczuk, and S. Topolewicz (2011), Features of a comet nucleus: The case of 103P/Hartley 2, Astron. Nachr. 332, 8, 785-794, DOI: 10.1002/asna.201111585.

Hand, K.P., C.F. Chyba, R.W. Carlson, and J.F. Cooper (2006), Clathrate hydrates of oxidants in the ice shell of Europa, Astrobiology 6, 3, 463-482, DOI: 10.1089/ast.2006.6.463.

Hersant, F., D. Gautier, and J.I. Lunine (2004), Enrichment in volatiles in the giant planets of the Solar System, Planet. Space Sci. 52, 7, 623-641, DOI: 10.1016/j.pss.2003.12.011.

Hsieh, H.H. (2010), Asteroids: A frosty finding, Nature 464, 7293, 1286-1287, DOI: $10.1038 / 4641286 \mathrm{a}$.

Jewitt, D., C.A. Garland, and H. Aussel (2008), Deep search for carbon monoxide in cometary precursors using millimeter wave spectroscopy, Astronom. J. 135, 1, 400-407, DOI: 10.1088/0004-6256/135/1/400.

Kossacki, K.J., and S. Szutowicz (2011), Comet 17P/Holmes: Possibility of a CO driven explosion, Icarus 212, 2, 847-857, DOI: 10.1016/j.icarus.2011. 01.007 .

Leliwa-Kopystyński, J., M. Maruyama, and T. Nakajima (2002), The waterammonia phase diagram up to $300 \mathrm{MPa}$ : Application to icy satellites, Icarus 159, 2, 518-528, DOI: 10.1006/icar.2002.6932. 
Luna, R., C. Millán, M. Domingo, and M.Á. Satorre (2008), Thermal desorption of $\mathrm{CH}_{4}$ retained in $\mathrm{CO}_{2}$ ice, Astrophys. Space. Sci. 314, 1-3, 113-119, DOI: 10.1007/s10509-008-9746-2.

Lunine, J.I., and D.J. Stevenson (1987), Clathrate and ammonia hydrates at high pressure: Application to the origin of methane on Titan, Icarus 70, 1, 61-77, DOI: 10.1016/0019-1035(87)90075-3.

Marboeuf, U., O. Mousis, J.M. Petit, and B. Schmitt (2010), Clathrate hydrates formation in short-period comets, Astrophys. J. 708, 1, 812-826, DOI: 10.1088/0004-637X/708/1/812.

Moses, J.I., K. Rawlins, K. Zahnle, and L. Dones (1999), External sources of water for Mercury's putative ice deposits, Icarus 137, 2, 197-221, DOI: 10.1006/ icar.1998.6036.

Richardson, M.I., and R.J. Wilson (2002), Investigation of the nature and stability of the Martian seasonal water cycle with a general circulation model, J. Geophys. Res. 107, E5, 7-1-7-28, DOI: 10.1029/2001je001536.

Roush, T.L. (2001), Physical state of ices in the outer solar system, J. Geophys. Res. 106, E12, 33315-33323, DOI: 10.1029/2000JE001334.

Rivkin, A.S., and J.P. Emery (2010), Detection of ice and organics on an asteroidal surface, Nature 464, 7293, 1322-1323, DOI: 10.1038/nature09028.

Vasavada, A.R., D.A. Paige, and S.E. Wood (1999), Near-surface temperatures on Mercury and the Moon and the stability of polar ice deposits, Icarus 141, 2, 179-193, DOI: 10.1006/icar.1999.6175.

Zheligovskaya, E.A., and G.G. Malenkov (2006), Crystalline water ices, Russ. Chem. Rev. 75, 1, 57-76, DOI: 10.1070/RC2006v075n01ABEH001184.

Received 19 March 2012

Received in revised form 18 December 2012 Accepted 4 January 2013 